\title{
Cenários do pior e alternativa ecossocialista*
}

\author{
Sceneries of the worst and an ecosocialist alternative
}

Michael Löwy**

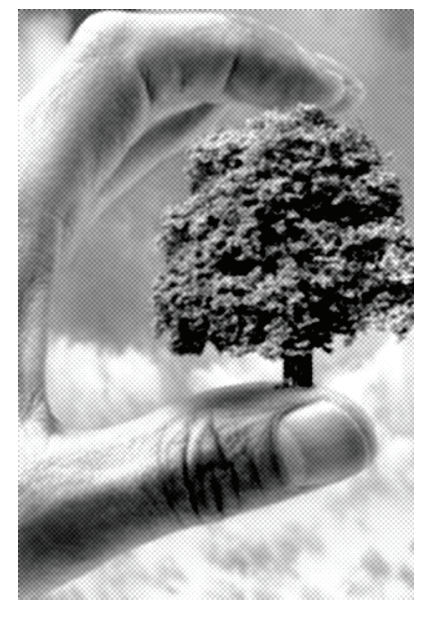

Resumo: O artigo define ecossocialismo e discorre sobre as mudanças necessárias nas forças produtivas da atual sociedade capitalista para se chegar às reformas ecossociais.

Palavras-chave: Ecossocialismo. Forças produtivas. Esquerda ecológica.

Abstract: The article presents the concept of ecosocialism, and there is also a discussion about the necessary changes in the productive forces of the current capitalism society in order to make the ecosocial reform.

Keywords: Ecosocialism. Productive forces. The ecological left.

* Tradução de Maria Helena C. V. Trylinski.

** É um pensandor brasileiro radicado na França, onde trabalha como diretor e pesquisador do Centre National de la Research Scientifique. Tem obras publicadas no Brasil pela Cortez Editora: As aventuras de Karl Marx contra o barão de Münchhausen (9. ed. rev. ampl.) e Ecologia e Socialismo. E-mail: lowym@free.fr 


\section{A mudança climática: cenários do pior}

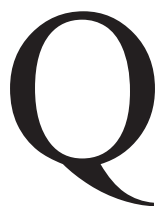

ual é a situação do planeta alguns meses antes da Conferência das Nações Unidas sobre Mudança Climática a ser realizada em Copenhague? Primeira constatação a ser feita a respeito dessa situação: tudo se acelera muito mais rápido do que o previsto. A acumulação de gás carbônico, a elevação da temperatura, o derretimento das geleiras polares e das "neves eternas", a desertificação das terras, as secas, as inundações, e mal a tinta dos documentos seca, as análises dos cientistas se revelam excessivamente otimistas. Cada vez mais, tende-se, nas previsões para o futuro próximo, para os extremos mais radicais. Não se fala mais - ou se fala cada vez menos - do que vai acontecer no fim do século, ou dentro de meio século, mas nos dez, vinte, trinta próximos anos. Não se trata mais apenas da questão do planeta que deixaremos para nossos filhos e netos, mas do futuro desta geração.

Um exemplo disto, bastante inquietante: se a geleira da Groenlândia derreter, o nível do mar poderia subir seis metros; isto significa a inundação não apenas de Dacca e de outras cidades marítimas asiáticas, mas também de Nova York, Amsterdã e Londres. Ora, estudos recentes mostram que a superfície da calota glacial da Groenlândia que derreteu é superior em $150 \%$ à média medida entre 1988 e 2006. ${ }^{1}$ Segundo Richard Alley, glaciologista da Penn State University, o derretimento da calota da Groenlândia, que se tinha o hábito de calcular em centenas de anos, poderia ocorrer em alguns decênios. ${ }^{2}$

Esta aceleração é, entre outras coisas, consequência de retroação (feedback). Alguns exemplos disso: 1) o derretimento das geleiras do Ártico — já bem começado - ao reduzir o albedo, isto é, o grau de reflexão da irradiação solar (que atinge seu ponto máximo nas superfícies brancas) - aumenta necessariamente a quantidade de calor que é absorvida pelo solo; cientistas calcularam que a redução de $10 \%$ do albedo do planeta equivaleria a aumentar cinco vezes o volume de $\mathrm{CO}_{2}$ na atmosfera; ${ }^{3}$ 2) a elevação da temperatura do mar transforma extensões imensas dos oceanos em desertos sem plânctons nem peixes, $o$

1. Trabalhos de Marco Tedesco, da Nasa, citados no Le Monde, de 14/12/2007.

2. Citado por Fred Pearce, The last generation, Reading, Eden Project Books, 2006, p. 83-90.

3. Cálculos de especialistas do Scripps Institution of Oceanography de San Diego, Califórnia, citados por Fred Pearce, The Last generation, p. 168. 
que reduz a capacidade que eles têm de absorver $\mathrm{CO}_{2}$. Conforme estudo recente, este fenômeno tornou-se quinze vezes mais rápido do que previsto nos modelos existentes. ${ }^{4}$

Outras possibilidades de retroação existem, ainda mais perigosas. Até agora pouco estudadas, elas não são consideradas nos modelos do Grupo intergovernamental de especialistas em Evolução do Clima (GIEC), porém podem causar uma mudança qualitativa brusca no efeito estufa: 1) pensemos nos 400 bilhões de toneladas de carbono no momento contidas no perglisol (permafrost), esta tundra congelada que se estende do Canadá à Sibéria. Se as geleiras começam a derreter, por que o perglisol (permafrost) não derreteria também? Ao se decompor, este carbono se transforma em metano, cujo efeito estufa é bem mais poderoso do que o do $\mathrm{CO}_{2} ; 2$ ) há também quantidades astronômicas de metano nas profundezas dos oceanos: pelo menos 1 trilhão de toneladas, sob a forma de clatrato de metano. Se a temperatura dos oceanos se elevar, é possível que esse metano seja liberado na atmosfera, provocando uma mudança brusca na transformação do clima. Além disso, esse gás é inflamável: pesquisadores russos observaram, no mar Cáspio, emissões de metano sob a forma de tochas ardentes que se erguem centenas de metros acima do mar. ${ }^{5}$ De acordo com o engenheiro químico Gregory Ryskin, uma irrupção maior de metano oceânico poderia gerar uma força explosiva 10 mil vezes mais potente do que a que produziria o estoque total de armas nucleares do planeta. ${ }^{6}$ Mark Lynas, que cita essa fonte, conclui que um planeta com seis graus a mais de temperatura seria bem pior que o Inferno descrito por Dante em A divina comédia... Acrescentemos que, segundo o último relatório do GIEC, a escalada da temperatura poderia ultrapassar os seis graus, até agora o mais alto previsto.

Todos esses processos começam de modo muito gradual, porém a partir de certo momento podem se desenvolver por meio de saltos qualitativos bruscos. A ameaça mais inquietante, cada vez mais antevista pelos pesquisadores é, então, a de um runaway climate change, ou seja, a de um movimento rápido e incontrolável do aquecimento. Há poucos cenários piores do que este, ou seja, de que o aumento da temperatura ultrapasse dois ou três graus: os cientistas

\footnotetext{
4. Le Monde, 5/2/2008, p. 8 .

5. Citadas por Fred Pearce, op. cit., p. 157.

6. Citado por Mark Lynas, Six degrees: our future on a hotter planet, Londres: Fourth Estate, 2007. p. 251.
} 
evitam desenhar quadros catastróficos, mas os riscos envolvidos já são conhecidos. A partir de certo nível de temperatura, a Terra ainda poderia ser habitada por nossa espécie? Infelizmente, não dispomos, neste momento, de um planeta de reserva no universo conhecido dos astrônomos...

A discussão desses “cenários do pior" não é um vão exercício apocalíptico: trata-se de perigos reais, é preciso avaliar toda a extensão deles. Não se trata tampouco de fatalismo: a situação ainda não é irremediável e ainda há tempo para agir e inverter o curso dos acontecimentos. Porém necessitamos do pessimismo da razão, em vez de ceder todo o espaço ao otimismo da vontade.

\section{As soluções das elites dirigentes}

Quem é o responsável por esta situação, inédita na história da humanidade? Os responsáveis são os seres humanos, nos respondem os cientistas. A resposta é adequada, porém um pouco limitada: os seres humanos habitam a Terra há milênios, a concentração de $\mathrm{CO} 2$ começou a tornar-se um perigo há apenas alguns decênios. Enquanto marxistas, respondemos esta pergunta do seguinte modo: a responsabilidade por isto cabe ao sistema capitalista, à sua lógica absurda e míope de expansão e acumulação sem limites, a seu produtivismo irracional obcecado pela procura do lucro. De fato, todo aparelho produtivo capitalista está baseado na utilização das energias fósseis - petróleo, carvão -, emissoras de gás responsável pelo efeito estufa; o mesmo se aplica ao sistema de transportes rodoviários, sobretudo ao longo das últimas décadas, e ao automóvel individual.

Que sugestões, que soluções, que alternativas são propostas pelos "responsáveis" por esta situação, ou seja, pelas elites capitalistas dirigentes? É pouco afirmar que elas não estão à altura do desafio. Pode-se classificar as posições dessas elites em três grandes grupos:

1) Grupo das avestruzes: constituído pelas elites que pretendem que a Terra é plana e que a mudança climática não possui origem "antrópica", não está ligada às atividades humanas. A mudança climática seria, por exemplo, consequência das manchas do Sol, ou teria outras explicações excêntricas. Esta era, há não muito tempo, a posição da administração Bush. Ela foi defendida por certo número, decrescente, de cientistas, alguns pesadamente subvenciona- 
dos pela indústria petrolífera. ${ }^{7}$ Tentou-se silenciar a opinião de cientistas "importunos" como James Hansen, o responsável pela questão do clima na Nasa. Esta cegueira a respeito do clima é uma batalha de retaguarda, que está perdendo alento.

2) Grupo dos partidários do business as usual: certamente, o problema existe, mas pode ser resolvido pelo envolvimento voluntário das empresas e por meio de medidas técnicas, sem que seja preciso que sejam tomadas decisões quantitativas embaraçosas. Esta posição pode vir acompanhada de uma espécie de "oportunismo" negocista: já que o aquecimento global é inevitável, tentemos tirar dele a maior vantagem que pudermos para nossos negócios.

A reação ao derretimento da banquisa ártica no verão é um exemplo claro da posição dos partidários do business as usual. O fenômeno ocorreu bem mais rapidamente que previsto: de acordo com as últimas observações científicas disponíveis (fevereiro de 2008), prevê-se a completa dissolução da banquisa não mais por volta de 2050, mas por volta de 2013! Como explicar esse aceleramento?

Segundo o cientista Jean Claude Gascard, coordenador do programa europeu de estudos do Ártico, ele deve-se, essencialmente, à diminuição do albedo: o oceano absorve mais calor que o gelo, que o reflete como um espelho. Em virtude da retroação, este derretimento provoca, portanto, uma nova elevação da temperatura do oceano. As coisas se alteram então muito mais rapidamente do que os modelos, em sua totalidade, haviam previsto. Vivemos o que deveria acontecer dentro de trinta ou quarenta anos. Todos trabalham para compreender por que os modelos não estão conformes com o que está acontecendo. ${ }^{8}$

Ora, que fazem os governos que têm limites com essa região, os Estados Unidos, a Rússia e o Canadá? Eles disputam, apoiados por expedições militares patrióticas, o traçado de zonas de soberania própria, tendo em vista a futura exploração do petróleo que jaz atualmente sob as geleiras...

Vejamos agora um outro exemplo interessante disso, que concerne à Comissão Europeia: um relatório confidencial apontava o perigo de inundação em certos países, tal como a Holanda, como consequência provável da elevação do

7. Há um capítulo eloquente a respeito desse climate change denial industry no livro de Georges Monbiot, Heat: how to stop the planet bruning. Londres: Allen Lane, 2006.

8. Le Monde, 23/2/2008, p. 7. 
nível do mar. Esse relatório aventava a hipótese de uma mudança maciça da população atingida pelo fenômeno, o que criaria oportunidades extraordinárias para a indústria da construção...

Que medidas técnicas poderiam fazer frente a essa ameaça? Aqui encontramos uma grande diversidade de sugestões. Algumas delas remetem à "geoengenharia" mais delirante: semear fertilizantes nos oceanos para ajudar o desenvolvimento rápido do plâncton; espalhar uma quantidade imensa de fragmentos de espelho para refletir o calor solar... A imaginação tecnocrática é bastante fértil. Uma outra vertente, mais clássica, propõe como alternativa a utilização de energia nuclear, que se supõe não produzir emissões. Só que para repor o conjunto das energias fósseis seria preciso construir centenas de centrais nucleares que trariam consigo uma quantidade inevitável de acidentes - um, dois, três Chernobyls - e uma massa astronômica de detritos radioativos — alguns com duração de milhares de anos - , sendo que ninguém sabe o que fazer com eles. Sem falar do risco considerável de proliferação das armas atômicas.

Mencionemos também o último remédio milagroso, defendido pelos Estados Unidos e pelo Brasil, mas que interessa também à Europa: substituir o petróleo, de qualquer modo destinado a acabar, pelos biocombustíveis. Os cereais ou o milho, em vez de alimentar os povos famintos do Terceiro Mundo, encheriam os tanques dos automóveis dos países ricos. Segundo a Food and Agriculture Organization (FAO), das Nações Unidas, o preço dos cereais já aumentou consideravelmente, em parte devido à forte demanda por biocombustíveis, destinando à fome milhões de pessoas dos países pobres. ${ }^{9}$ Acrescentemos que, de acordo com um número crescente de cientistas, o inventário do carbono na maioria desses carburantes de origem agrícola não é realmente favorável, e a produção deles gera, devido aos fertilizantes, ao transporte, tanta emissão quanto a que eles supostamente economizam (na comparação com o petróleo). Isto sem mencionar o desmatamento que a produção agrocapitalista já está provocando no Brasil e na Indonésia. A substituição do petróleo pelos biocombustíveis não passa de uma tentativa baldada de salvar um sistema de transporte irracional baseado no automóvel e no caminhão.

A mais interessante dessas soluções-milagre técnicas é a captura e o sequestro do carbono, que concerne em especial às centrais elétricas. Contudo,

9. FAO, La situation mondiale de l'alimentation et de l'agriculture 2008, p. 98. Disponível em: <ftp:// ftp.fao.org/docrep/fao/011/i0100f/i0100f06.pdf>. 
até o momento conhece-se apenas algumas raras experiências locais, e muitos especialistas duvidam da eficácia desse método.

3) Grupo dos acordos internacionais restritivos. É o caso de Kyoto, sustentado notadamente pelos governos europeus. Kyoto representa, de certo modo, um verdadeiro avanço por ter como modelo acordos internacionais com objetivos quantitativos especificados e penalidades previstas no caso de não cumprimento desses objetivos. Dito isto, seu dispositivo central, o "Mercado dos Direitos de Emissão" revelou-se bem decepcionante: a Europa, ou seja, o grupo de países mais comprometido com a causa ambiental só conseguiu, em dez anos, reduzir as emissões em 2\%. Não se vê como ela poderá atingir em 2012 o objetivo declarado de $8 \%$ - objetivo tão modesto que não terá praticamente nenhuma implicação sobre o efeito estufa. ${ }^{10}$ Este fracasso não é um acaso: as cotas de emissão distribuídas pelos "responsáveis" eram tão generosas que todos os países encerraram o ano de 2006 com grandes excedentes de "direitos de emissão". Resultado: o preço da tonelada de $\mathrm{CO}_{2}$ desabou de vinte euros em 2006 para menos de um euro em 2007... Outro dispositivo de Kyoto, os "Mecanismos de Desenvolvimento Sustentável" - intercâmbio entre direitos de emissão no Norte e investimentos "limpos" nos países do Sul — não tem, segundo opinião generalizada, senão um alcance limitado, pois não pode ser fiscalizado e serve para encobrir todo tipo de negociatas e abusos. ${ }^{11}$

Não obstante, uma das virtudes de Kyoto consiste em colocar a questão da mudança climática no terreno político. Eis aqui uma boa notícia: o ex-dirigente do governo conservador da Austrália, John Howard, um amigo de George Bush e um negador obstinado do aquecimento do planeta, acaba de perder as eleições para seu adversário trabalhista, que se comprometeu a assinar os acordos de Kyoto: é a primeira vez na história de um país que a questão da mudança climática desempenha um papel importante em uma eleição.

Em dezembro de 2009, em Copenhague, será realizada a Conferência das Nações Unidas sobre Mudança Climática. Podemos esperar um despertar tardio por parte das oligarquias dominantes? Nada pode ser descartado, mas até ago-

10. Cf. Le Monde, 7/12/2007, p. 7.

11. Sobre os limites de Kyoto e, em geral, da crise da mudança climática, indico o excelente dossiê redigido e organizado pela revista Inprecorr (n. 525, mar. 2007) por Daniel Tanuro sob o título "Le capitalisme contre le climat". 
ra todas as propostas oficiais - o relatório Stern ${ }^{12}$ é um exemplo claro disto - revelam-se inteiramente incapazes de reverter o curso das coisas, pois estão obstinadamente encerradas na lógica da economia de mercado capitalista. Como constata Hervé Kampf, jornalista do jornal Le Monde, em sua interessante obra Comment les riches détruisent la planète: "o sistema social que rege atualmente a sociedade humana, o capitalismo, resiste cegamente às mudanças que precisam ser operadas se quisermos garantir à existência humana sua dignidade e sua esperança". ${ }^{13}$

Para enfrentar as implicações da mudança climática e da crise ecológica em geral (da qual os exemplos que expusemos são a expressão mais ameaçadora), é preciso uma mudança radical e estrutural que toque os fundamentos do sistema capitalista: uma transformação não apenas das relações de produção (a propriedade privada dos meios de produção), mas também das forças produtivas (os meios técnicos e o saber fazer humano que concorrem para a produção). Isto implica, em primeiro lugar, uma verdadeira revolução no sistema energético, no sistema dos transportes e nos modos de consumo atuais, baseados no desperdício e no consumo ostentatório, instigados pela publicidade. Em resumo, trata-se de uma mudança paradigmática da civilização e da transição para uma nova sociedade, onde a produção seria democraticamente planejada pela população, isto é, onde as decisões mais importantes sobre as prioridades da produção e do consumo não seriam ditadas por um punhado de exploradores, ou pelas forças cegas do mercado, nem por uma oligarquia de burocratas e de especialistas, mas pelos trabalhadores e pelos consumidores. Numa palavra, pela população, após um debate democrático em que se admite discussão entre diferentes propostas. É isto o que chamamos de ecossocialismo.

\section{A alternativa ecossocialista}

O que é, então, o ecossocialismo? Trata-se de uma corrente de pensamento e de ação ecológica que se apropria dos conhecimentos adquiridos funda-

12. Relatório sobre a economia da mudança climática redigido pelo economista Nicholas Stern para o governo britânico em 2006. Disponível em inglês em: <http://www.hm-treasury.gov.uk/stern-review-report. htm>. Para resumo em francês, disponível em: <http://www.hm-treasury.gov.uk/d/stern-longsummary-french.pdf $>$.

13. Hervé Kempf, Comment les riches détruisent la planète. Paris: Seuil, 2007. p. 8. 
mentais do socialismo, mas do socialismo desvencilhado de seus resíduos produtivistas. Para os ecossocialistas, a lógica do mercado e do lucro, bem como a lógica do autoritarismo burocrático do finado "socialismo real", são incompatíveis com as exigências de proteção do meio natural. Apesar de criticar a ideologia das correntes dominantes do movimento operário, os ecossocialistas sabem que os trabalhadores e suas organizações são uma força essencial para qualquer transformação radical do sistema, e para o estabelecimento de uma nova sociedade, socialista e ecológica.

O ecossocialismo desenvolveu-se, sobretudo, ao longo dos últimos trinta anos, graças aos trabalhos de pensadores do porte de Manuel Sacristan, Raymond Williams, Rudolf Bahro (em seus primeiros escritos) e André Gorz (idem), bem como das preciosas contribuições de James O'Connor, Barry Commoner, Hohn Bellamy Foster, Joel Kovel (EUA), Juan Martinez Allier, Francisco Fernandez Buey, Jorge Riechman (Espanha), Jean-Paul Déléage, Jean-Marie Harribey, Pierre Rousset (França), Elmar Altvater, Frieder Otto Wolf (Alemanha) e muitos outros pensadores que se manifestam através de uma rede de revistas como Capitalism, Nature and Socialism, Ecologia Politica etc.

Esta corrente está longe de ser politicamente homogênea, porém a maior parte de seus representantes compartilha alguns temas comuns. Em ruptura com a ideologia produtivista do progresso - na sua forma capitalista e/ou burocrática - e contrária à expansão sem limite de um modo de produção e de consumo destruidor da natureza, ela representa uma tentativa original de articular as ideias fundamentais do marxismo com os conhecimentos da crítica ecológica.

James O'Connor caracteriza como ecossocialistas as teorias e os movimentos que aspiram subordinar o valor de troca ao valor de uso, ${ }^{14}$ para tanto organizando a produção em virtude das necessidades sociais e das exigências de proteção do meio ambiente. O objetivo deles - um socialismo ecológico - seria uma sociedade ecologicamente racional baseada no controle democrático, na igualdade social e na predominância do valor de uso. ${ }^{15}$ Eu acrescentaria que: a) esta sociedade exige a propriedade coletiva dos meios de produção, um planejamento democrático que permita à sociedade fixar os objetivos da pro-

14. O valor de uso de uma mercadoria corresponde à utilidade dela, à sua capacidade de satisfazer uma necessidade enquanto que seu valor de troca é representado pelo preço relativo dela.

15. James O'Connor. Natural causes. Essays in ecological marxism. Nova York: The Guilford Press, 1998. p. 278-331. 
dução e os investimentos e estabelecer uma nova estrutura tecnológica das forças produtivas; b) que o ecossocialismo seria um sistema baseado na satisfação das necessidades humanas democraticamente definidas, mas seria também um sistema baseado na gestão racional coletiva das trocas de matérias com o meio ambiente, respeitando-se os ecossistemas.

O ecossocialismo desenvolve portanto uma crítica da tese da "neutralidade" das forças produtivas que predominou na esquerda do século XX, em suas duas vertentes: a social-democrata e a comunista soviética. Esta crítica poderia inspirar-se, na minha opinião, nas observações de Marx sobre a Comuna de Paris: os trabalhadores não podem se apoderar do aparelho do Estado capitalista e pô-lo a funcionar a seu serviço. Eles devem "despedaçá-lo" e substituí-lo por um outro, de natureza completamente distinta, uma forma não governamental e democrática de poder político.

O mesmo se aplica, mutatis mutandis, ao aparelho produtivo: por sua natureza, e sua estrutura, ele não é neutro, mas está a serviço da acumulação de capital e da expansão ilimitada do mercado. Opõe-se aos imperativos de defesa do meio ambiente e da saúde da força de trabalho. É preciso então fazer com que passe por uma "revolução", que o transformará radicalmente. Isto pode significar que certos ramos da produção - as centrais nucleares, por exemplo — deverão ser "feitos em pedaços". Em todo caso, as próprias forças produtivas devem ser profundamente modificadas. Evidentemente, muitos conhecimentos científicos e tecnológicos do passado são preciosos, porém o conjunto do sistema produtivo deve ser questionado do ponto de vista de sua compatibilidade com as exigências vitais de preservação do equilíbrio ecológico.

Isto implica, antes de tudo, uma revolução energética: a substituição das energias não renováveis (carvão, petróleo e energia nuclear) e responsáveis pela poluição, pelo envenenamento do meio ambiente e pelo aquecimento do planeta, por energias "alternativas", "limpas" e renováveis (água, vento, sol), e a redução drástica do consumo de energia (e, portanto, das emissões de $\mathrm{CO}_{2}$ ).

Porém é o conjunto do modo de produção e de consumo - baseado por exemplo no automóvel individual e em outros produtos desse tipo - que deve ser transformado com a supressão das relações de produção capitalistas e o início de uma transição para o socialismo. Entendo por socialismo a ideia inicial, comum a Marx e aos socialistas libertários (que não tem muito a ver com os pretensos regimes "socialistas" que ruíram a partir de 1989), de uma "utopia 
concreta" (para utilizar o conceito de Ernst Bloch), a ideia de uma sociedade sem classes e sem dominação onde os principais meios de produção pertencem à coletividade, e as principais decisões sobre investimento, sobre a produção e a distribuição não se encontram entregues às leis cegas do mercado, a uma elite de proprietários, ou a uma camarilha burocrática, mas são tomadas pelo conjunto da população após um amplo debate democrático e pluralista. A aposta planetária deste processo de transformação radical das relações dos humanos entre si e com a natureza é uma mudança de paradigma civilizacional que concerne não apenas ao aparelho produtivo e aos hábitos de consumo, mas também ao habitát, à cultura, aos valores, ao estilo de vida.

Que destino terão as forças produtivas nessa transição para o socialismo — um processo histórico que não se conta em meses ou anos?

Quanto a esta problemática, duas escolas se defrontam no seio do que poder-se-ia chamar de esquerda ecológica:

1) A escola otimista, segundo a qual, graças ao progresso tecnológico e às energias limpas, o desenvolvimento das forças produtivas socialistas pode conhecer uma expansão ilimitada, com o objetivo de satisfazer a "cada um conforme suas necessidades". Esta escola não leva em consideração os limites naturais do planeta e acaba por reproduzir, sob a etiqueta "desenvolvimento sustentável", o modelo socialista antigo.

2) A escola pessimista, que, partindo desses limites naturais, considera que é preciso limitar, de maneira draconiana, o crescimento demográfico e o padrão de vida das populações. Seria preciso tomar a via do decrescimento, às custas da renúncia às habitações individuais, ao aquecimento etc. Dado que essas medidas são altamente impopulares, esta escola algumas vezes adula o sonho de uma "ditadura ecológica esclarecida".

Parece-me que essas duas escolas compartilham uma concepção puramente quantitativa de "crescimento" ou do desenvolvimento das forças produtivas. Há uma terceira posição, que me parece mais apropriada, cuja proposta principal é a mudança qualitativa do desenvolvimento.Trata-se de dar um basta ao monstruoso desperdício de recursos pelo capitalismo, desperdício ancorado na produção em grande escala de produtos inúteis ou prejudiciais. A indústria armamentista é um exemplo evidente disto. Trata-se, por conseguinte, de orientar a produção para a satisfação das necessidades autênticas, a começar pelas que podemos apontar como necessidades "bíblicas": água, alimentação, vestimen- 
ta, habitação, necessidades às quais é preciso acrescentar, bem-entendido, a saúde, a educação e a cultura.

Como separar as necessidades autênticas das artificiais e criadas? Estas últimas são induzidas pelo sistema de manipulação mental que se chama "publicidade". Peça indispensável ao funcionamento do mercado capitalista, a publicidade está fadada a desaparecer em uma sociedade de transição para o socialismo para ser substituída pela informação fornecida pelas associações de consumidores. O critério para se distinguir uma necessidade autêntica de uma artificial é sua persistência após a supressão da publicidade... (Coca-cola!).

O automóvel individual, pelo contrário, corresponde a uma necessidade real, porém em um projeto ecossocialista, fundado na abundância de transporte público gratuito, ele terá um papel bem menor do que na sociedade burguesa, onde se tornou um fetiche mercantil, um sinal de prestígio e o centro da vida social dos indivíduos.

Mas, responderão os pessimistas, os indivíduos são movidos por desejos e por aspirações infindas, que é preciso controlar e reprimir. Ora, o ecossocialismo está escorado em uma aposta, que já era a aposta de Marx: a predominância, em uma sociedade sem classes, do "ser" sobre o "ter", ou seja, a predominância da realização pessoal, por meio de atividades culturais lúdicas, eróticas, esportivas, artísticas, políticas, em vez da predominância do desejo de acumulação infinda de bens e de produtos. Este último é instigado pelo fetichismo da mercadoria inerente ao sistema capitalista, pela ideologia dominante e pela publicidade: nada indica que ele constitui um traço da "natureza humana eterna".

Isto não quer dizer que não haverá conflitos entre as exigências da proteção do meio ambiente e as necessidades sociais, entre os imperativos ecológicos e as necessidades de desenvolvimento, notadamente nos países pobres. Cabe à democracia socialista, liberta dos imperativos do capital e do "mercado", resolver essas contradições.

Sim, nos responderão alguns, ela é simpática, esta utopia. Mas, enquanto esperamos, devemos ficar de braços cruzados? Certamente não! É preciso lutar por cada avanço, por cada medida de regulamentação das emissões de gás de efeito estufa, por cada ação de defesa do meio ambiente.

A luta por reformas ecossociais pode ser portadora de uma dinâmica de mudança, desde que sejam rechaçados os argumentos e as pressões dos interes- 
ses dominantes apresentados em nome das "regras do mercado", da "competitividade" ou da "modernização".

Algumas exigências imediatas já podem ser, ou podem rapidamente tornar-se, um ponto de convergência entre movimentos sociais e ecológicos, entre sindicatos e defensores do meio ambiente, entre "vermelhos" e "verdes". É o caso das exigências que muitas vezes "prefiguram" o que poderia ser uma sociedade ecossocialista:

- a substituição paulatina das energias fósseis por fontes de energia "limpas", especialmente a energia solar;

- a promoção do transporte público - trens, metrôs, ônibus, bondes - barato ou gratuito como alternativa à asfixia e à poluição das cidades e do campo pelo automóvel individual e pelo sistema de transporte rodoviário;

- a luta contra o sistema da dívida e dos "ajustes" ultraliberais impostos pelo FMI e pelo Banco Mundial aos países do Sul e suas consequências sociais e ecológicas dramáticas: desemprego em massa, eliminação da proteção social e das culturas de subsistência, destruição dos recursos naturais em virtude de sua exploração;

- defesa da saúde pública: medidas contra a poluição do ar, da água (dos lençóis freáticos), dos alimentos em razão da avidez das grandes empresas capitalistas;

— desenvolvimento subvencionado da agricultura orgânica em lugar da agroindústria;

- redução da jornada de trabalho como resposta ao desemprego e como visão de uma sociedade que privilegia o tempo livre na comparação com a acumulação de bens. ${ }^{16}$

A lista das medidas necessárias existe, mas é difícil que ela seja compatível com o neoliberalismo e a submissão aos interesses do capital... Em uma dinâmica de radicalização crescente, cada vitória parcial é importante para um objetivo superior. Cada ganho nessa batalha é precioso, não apenas porque retarda a corrida em direção ao abismo, mas porque permite aos indivíduos,

16. Ver Pierre Rousset. “Convergence de combats. L'écologie et le social”, Rouge, p. 8-9, 16 maio 1996. 
homens e mulheres, e em especial aos trabalhadores e às comunidades locais, e mais particularmente ainda aos camponeses e indígenas, se organizar, lutar e tomar consciência das implicações da luta. Graças a sua experiência coletiva, eles poderão tomar consciência da falência do sistema capitalista e da necessidade de uma mudança de civilização.

Artigo recebido em ago./2010 - Aprovado em set./2010 